\title{
Photosynthetic Properties and Response to Drought in Cucumber Seedlings Acclimatized to Different Vapor-pressure-deficit Levels
}

\author{
Toshio Shibuya*, Kenji Kano, Ryosuke Endo and Yoshiaki Kitaya \\ Graduate School of Life and Environmental Sciences, Osaka Prefecture University, Sakai 599-8531, Japan
}

\begin{abstract}
Hardening with a high vapor-pressure-deficit (VPD) can decrease conductance $\left(g_{\mathrm{s}}\right)$ and thereby enhance drought tolerance by reducing transpiration, which is particularly useful during transplant establishment. However, high-VPD hardening may decrease photosynthetic performance due to stomatal (diffusion) and nonstomatal (mesophyll) limitation. If $g_{\mathrm{s}}$ can be lowered without significantly reducing photosynthesis, water-use efficiency (WUE $=\mathrm{CO}_{2}$ assimilation/transpiration), which is an important criterion for transplant quality, would improve. We investigated the photosynthetic properties of cucumber (Cucumis sativus L.) leaves acclimatized to different VPD levels $\left(0.4\right.$ and $3.2 \mathrm{kPa}$ at $\left.28^{\circ} \mathrm{C}\right)$, and determined whether photosynthesis was limited by stomatal or non-stomatal factors at high VPD. The net photosynthetic rate $\left(P_{n}\right)$ and $g_{\mathrm{s}}$ were measured at a VPD of $0.8 \mathrm{kPa}$ and a leaf temperature of $28^{\circ} \mathrm{C}$ under saturating light. The photosynthetic response to the intercellular $\mathrm{CO}_{2}$ concentration $\left(C_{\mathrm{i}}\right)$ was used to quantify the effects of VPD acclimatization on carboxylation efficiency. $P_{\mathrm{n}}$ did not differ significantly between acclimatization VPDs, but $g_{\mathrm{s}}$ was much lower $(\times 0.36)$ in high-VPD leaves at an ambient $\mathrm{CO}_{2}$ concentration of $400 \mu \mathrm{mol} \cdot \mathrm{mol}^{-1}$. Thus, the intrinsic WUE (= $\left.P_{\mathrm{n}} / g_{\mathrm{s}}\right)$ of the high-VPD leaves was much higher $(\times 2.85)$. The $C_{\mathrm{i}}$ of high-VPD seedlings was lower than that of low-VPD seedlings, but, this did not cause any significant reduction in $P_{n}$ in the high-VPD treatments because the decrease in $C_{\mathrm{i}}$ occurred within a range in which photosynthesis was not limited by ribulose-1,5bisphosphate carboxylation in this experiment. The $P_{\mathrm{n}}-C_{\mathrm{i}}$ curve did not differ between the VPD treatments, indicating that carboxylation efficiency was not affected. When VPD-acclimatized seedlings experienced a limited water supply, the low-VPD leaves showed lower leaf water potential and more severe wilting than the high-VPD leaves 30 min after water limitation began. The $g_{\mathrm{s}}$ of the high-VPD leaves was significantly lower (approximately $\times 0.5$ in average) than that of the low-VPD leaves throughout the water-supply-limitation treatment. The lower $g_{\mathrm{s}}$ maintained the water status of the high-VPD leaves at less-wilting levels by decreasing transpiration. These results indicate that high-VPD hardening could enhance the tolerance to short-term drought without stomatal or non-stomatal limitation of photosynthesis when controlling $g_{\mathrm{s}}$ effectively.
\end{abstract}

Key Words: carboxylase activity, hardening, intercellular $\mathrm{CO}_{2}$ concentration, stomatal conductance, water-use efficiency.

\section{Introduction}

The atmospheric moisture content influences leaf gas-exchange properties via its effects on stomatal dynamics in many species (Buckley, 2005; El-Sharkawy et al., 1985). Hardening with a high vapor-pressuredeficit (VPD) can decrease stomatal conductance $\left(g_{\mathrm{s}}\right)$

Received; March 14, 2016. Accepted; September 26, 2016.

First Published Online in J-STAGE on October 27, 2016.

This research was supported by a Japan Society for the Promotion of Science Grant-in-Aid for Scientific Research (B) (KAKENHI 24380140, KAKENHI 15H04575).

* Corresponding author (E-mail: shibuya@envi.osakafu-u.ac.jp). and thereby enhance drought tolerance by reducing transpiration, which is particularly useful during transplant establishment in horticultural production (Bañon et al., 2006; Sánchez-Blanco et al., 2004; Shibuya et al., 2003, 2006). If the net photosynthetic rate $\left(P_{\mathrm{n}}\right)$ is not affected, acclimatization at high VPD can improve wateruse efficiency (WUE), which is an important criterion for transplant quality: carbohydrate accumulation combined with efficient water use is advantageous when transplanted seedlings experience a water deficit. However, high-VPD acclimatization may limit photosynthesis through both stomatal (diffusion) and non-stomatal (mesophyll) factors (Dai et al., 1992; Flexas and Medrano, 2002; Raschke and Resemann, 1986). In the 
former case, high VPD may decrease $g_{\mathrm{s}}$ and thereby limit $\mathrm{CO}_{2}$ assimilation by decreasing the intercellular $\mathrm{CO}_{2}$ concentration $\left(C_{\mathrm{i}}\right)$ due to decreased gas exchange through the stomata. In the latter case, the higher evaporative demand may decrease the leaf's water potential $\left(\Psi_{1}\right)$ and consequently inhibit carboxylation activity in the chloroplasts (Keck and Boyer, 1974; Lawlor, 2002).

Despite these potential limitations, Carins Murphy et al. (2014) reported that high VPD did not decrease photosynthesis by Toona ciliata when $g_{\text {s }}$ decreased to maintain transpiration, implying that neither stomatal nor non-stomatal factors limited photosynthesis even under high-VPD conditions. Two hypotheses may explain this observation. The first is that the decrease in $C_{\mathrm{i}}$ caused by a reduction in $g_{\mathrm{s}}$ would not significantly decrease $\mathrm{CO}_{2}$ assimilation when the decrease occurred within a range in which photosynthesis was mainly limited by ribulose-1,5-bisphosphate (RuBP) regeneration, but was not limited by RuBP carboxylation; in the latter reaction, photosynthesis would be strongly influenced by $C_{\mathrm{i}}$. The $g_{\mathrm{s}}$ and $C_{\mathrm{i}}$ may be altered by VPD via changes in stomatal size and distribution (Carins Murphy et al., 2014; Hovenden et al., 2012) in addition to the stomatal aperture. The second hypothesis is that the high-VPD acclimatization does not lower $\Psi_{1}$ when the water supply is sufficient and transpiration is suppressed sufficiently by stomatal closure to prevent the development of water stress (Carins Murphy et al., 2014; Itagaki et al., 2014). In this case, high-VPD acclimatization can only weakly inhibit carboxylation activity.

In the present study, we investigated the photosynthetic properties including gas exchange $\left(P_{\mathrm{n}}, g_{\mathrm{s}}\right.$, and $\left.C_{\mathrm{i}}\right)$ and carboxylation activity of cucumber (Cucumis sativus L.) leaves acclimatized to different VPD levels, and determined whether photosynthesis was limited by stomatal or non-stomatal factors at high VPD. In addition, the short-term response to a water deficit in the acclimatized seedlings was evaluated by measuring changes in stomatal conductance and water status during water-supply limitation.

\section{Materials and Methods}

\section{Plant growth conditions}

'Hokushin' cucumber seeds were sown in vermiculite in plastic pots $(60 \mathrm{~mm}$ in diameter, $55 \mathrm{~mm}$ in depth) and germinated at $28^{\circ} \mathrm{C}, 90 \%$ relative humidity $(\mathrm{RH})$, a photosynthetic photon flux (PPF) of $300 \mu \mathrm{mol} \cdot \mathrm{m}^{-2} \cdot \mathrm{s}^{-1}$, and a photoperiod of 16:8-h L:D. The seedlings were maintained in growth chambers (custom model; Ikeya Co., Kashiba, Japan) at $28^{\circ} \mathrm{C}$ under a high VPD $(3.2 \mathrm{kPa})$ or a low VPD $(0.4 \mathrm{kPa})$, which were equivalent to $15 \%$ and $90 \% \mathrm{RH}$, respectively, immediately after germination. Illumination was supplied by fluorescent lamps (FPL55EX-N; Panasonic Corp., Kadoma, Japan). The pots were placed in nutrient solution (the A-type recipe of OAT Solution; OAT Agrio Co. Ltd.,
Tokyo, Japan) to a depth of 10 to $20 \mathrm{~mm}$. At high VPD, the surface of the vermiculite was covered by plastic film to minimize evaporation. The moisture level was almost saturated in the growing medium of all treatments.

\section{Measurements of photosynthetic properties and leaf water status}

When the first true leaves had expanded and the second leaves had begun to emerge (10 days after seeding in the high-VPD treatment, 8 days after seeding in the low-VPD treatment), $P_{\mathrm{n}}$ and $g_{\mathrm{s}}$ of the first true leaf (approximately $36 \mathrm{~cm}^{2}$ for the first true leaf in both treatments) in 10 seedlings were measured using an LI-6400 photosynthesis system (LI-COR Inc., Lincoln, NE, USA). A comparison between plants at the same developmental stage but of different ages was preferred when the rate of plant development was different between the treatments. The measurements were conducted at ambient $\mathrm{CO}_{2}$ concentrations $\left(C_{\mathrm{a}}\right)$ of $50,100,150,200,400$, and $800 \mu \mathrm{mol} \cdot \mathrm{mol}^{-1}$ to determine $P_{\mathrm{n}}-C_{\mathrm{i}}$ curves. Illumination was supplied at a saturating PPF of $2000 \mu \mathrm{mol} \cdot \mathrm{m}^{-2} \cdot \mathrm{s}^{-1}$ by red and blue LEDs at a ratio of $9: 1$. The measurements began after reaching an equilibrium between $P_{\mathrm{n}}$ and $g_{\mathrm{s}}$ under the specified light intensity, which typically occurred within $10 \mathrm{~min}$. In the leaf chamber of the measuring system, the leaf temperature and VPD were maintained at $28^{\circ} \mathrm{C}$ and $0.8 \mathrm{kPa}(80 \%$ $\mathrm{RH})$, respectively. During the measurements, $C_{\mathrm{a}}$ was progressively decreased from $400 \mu \mathrm{mol} \cdot \mathrm{mol}^{-1}$ to the lower values, and then increased to $800 \mu \mathrm{mol} \cdot \mathrm{mol}^{-1}$. $C_{\mathrm{i}}$ was calculated according to the method of von Caemmerer and Farquhar (1981). The maximum rate of Rubisco carboxylase activity $\left(V_{\text {cmax }}\right)$ and the electron transport rate $(J)$ were estimated from $P_{\mathrm{n}}-C_{\mathrm{i}}$ curves using a curve-fitting model developed by Sharkey et al. (2007). The intrinsic WUE (WUE $)_{\mathrm{i}}$ ) was calculated by dividing $P_{\mathrm{n}}$ by $g_{\mathrm{s}}$ (Chaves et al., 2004). $\Psi_{1}$ was measured for another five seedlings in each treatment group using a dewpoint potentiometer (WP4-T; Decagon Devices, Inc., Pullman, WA, USA) immediately after VPD acclimatization.

\section{Microscopic observation of the leaf surface}

Imprints of the adaxial and abaxial surfaces of another five first true leaves were obtained by spreading a liquid adhesive (Ekiban A; Taihei Yakuhin Co., Ltd., Tokyo, Japan) onto the leaf surface, allowing it to dry, and then peeling the adhesive from the leaf. The imprints were observed using a VHX-1000 digital microscope (Keyence Corp., Osaka, Japan) at 1000× magnification, and the numbers of stomata and epidermal cells in three randomly selected fields of view in each leaf were counted. The average for these fields of view was then calculated. The stomatal lengths were measured using image-processing software provided with the microscope (VHX-H1M1; Keyence Corp.). 
The stomatal and epidermal densities were calculated by dividing the number of stomata and epidermal cells, respectively, by the area of the field. The stomatal length was measured using the image-processing software, and the stomatal index was defined as the number of stomata in a given area divided by the total number of stomata plus epidermal cells in that area (Casson et al., 2009).

\section{Effect of acclimatization VPD on short-term response to drought}

Five seedlings that had been acclimatized to high VPD for 10 days and five that had been acclimatized to low VPD for 8 days were exposed to a limited water supply immediately after VPD acclimatization to evaluate the effect of acclimatization VPD on the short-term $(<30 \mathrm{~min})$ response to a water deficit. The roots of the seedlings were cleaned by quickly washing away the vermiculite growing medium, and were then exposed to saturated vapor conditions by inserting the roots in a closed plastic bottle containing a wetted paper towel. The shoots of the seedlings were then maintained in the growth chamber at $28^{\circ} \mathrm{C}$ under a VPD of $1.9 \mathrm{kPa}$ (approximately $50 \% \mathrm{RH}$ ). Illumination was supplied by fluorescent lamps at a PPF of $300 \mu \mathrm{mol} \cdot \mathrm{m}^{-2} \cdot \mathrm{s}^{-1}$. The adaxial and abaxial $g_{\mathrm{s}}$ of the first true leaf in each seedling were measured for $30 \mathrm{~min}$ at 3 -min intervals using a SC-1 porometer (Decagon Devices, Inc.). The porometer was used instead of the LI-6400 for quick measurements. The $\Psi_{1}$ of the plants $(\mathrm{n}=5)$ in each treatment group was measured using the dewpoint potentiometer $30 \mathrm{~min}$ after starting the water supply limitation.

\section{Statistical analysis}

Significant differences between treatment means were identified using the Student's $t$-test. Statistical analyses were performed using the Statcel 2 software program (OMS Publishing Inc., Tokorozawa, Japan). The measurements of photosynthetic properties were repeated twice at different times. The other measurements were not repeated, but were conducted under a precisely controlled environment.

\section{Results}

\section{Photosynthetic properties and water status}

There was no significant difference in $P_{\mathrm{n}}$ between acclimatization VPDs, but $g_{\mathrm{s}}$ was much lower $(\times 0.36)$ in the high-VPD leaves at $C_{\mathrm{a}}$ of $400 \mu \mathrm{mol} \cdot \mathrm{mol}^{-1}$ (Table 1). $C_{\mathrm{i}}$ of high-VPD seedlings was lower $(\times 0.91)$ than that of low-VPD seedlings (Table 1). The WUE $\mathrm{W}_{\mathrm{i}}$ of the highVPD leaves was 2.85 times that of the low-VPD leaves (Table 1). The $P_{\mathrm{n}}-C_{\mathrm{i}}$ curve did not differ between the VPD treatments (Fig. 1). The $V_{\text {cmax }}$ and $J$ did not differ significantly between the two treatments (Table 1). In addition, $\Psi_{1}$ did not differ significantly between the acclimatization VPDs (Table 1). Similar results of photosynthesis were obtained after repeating the experiment at different times (data not shown).

\section{Microscopic observation of the leaf surface}

The adaxial and abaxial stomatal densities were sig-

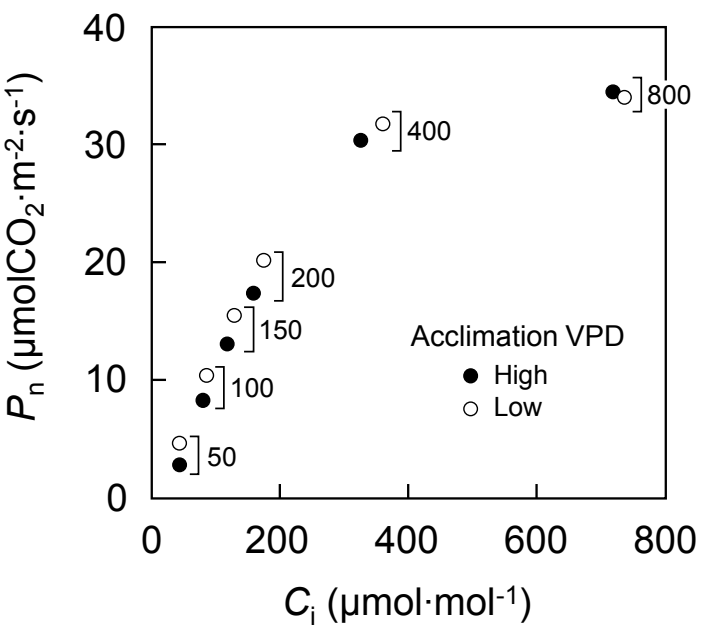

Fig. 1. Relationships between the intercellular $\mathrm{CO}_{2}$ concentration $\left(C_{\mathrm{i}}\right)$ and the net photosynthetic rate $\left(P_{\mathrm{n}}\right)$ for Cucumis sativus leaves acclimatized to a high $(3.2 \mathrm{kPa})$ or low $(0.4 \mathrm{kPa})$ vaporpressure-deficit (VPD). Photosynthesis was measured at a PPF of $2000 \mu \mathrm{mol} \cdot \mathrm{m}^{-2} \cdot \mathrm{s}^{-1}$, ambient $\mathrm{CO}_{2}$ concentrations $\left(C_{\mathrm{a}}\right)$ of 50 , $100,150,200,400$, and $800 \mu \mathrm{mol} \cdot \mathrm{mol}^{-1}$, a leaf temperature of $28^{\circ} \mathrm{C}$, and a VPD of $0.8 \mathrm{kPa}(80 \%$ relative humidity). Values are the means of 10 replicate plants. The values at the right side of the plots are $C_{\mathrm{a}}$ for measurement. The $P_{\mathrm{n}}$ and $g_{\mathrm{s}}$ measured at $C_{\mathrm{a}}$ of $400 \mu \mathrm{mol} \cdot \mathrm{mol}^{-1}$ are the same data as in Table 1.

Table 1. Net photosynthetic rate $\left(P_{\mathrm{n}}\right)$, stomatal conductance $\left(g_{\mathrm{s}}\right)$, intercellular $\mathrm{CO}_{2}$ concentration $\left(C_{\mathrm{i}}\right)$, intrinsic water-use efficiency (WUE $\mathrm{i}_{\mathrm{i}}=$ $\left.P_{\mathrm{n}} / g_{\mathrm{s}}\right)$, maximum rate of Rubisco carboxylase activity $\left(V_{\mathrm{cmax}}\right)$, electron transport rate $(J)$, and leaf water potential $\left(\Psi_{1}\right)$ of first true leaves of Cucumis sativus acclimatized to high (3.2 kPa) or low (0.4 kPa) vapor-pressure-deficit (VPD).

\begin{tabular}{|c|c|c|c|c|c|c|c|}
\hline $\begin{array}{l}\text { Acclimatization } \\
\text { VPD }\end{array}$ & $\begin{array}{c}P_{\mathrm{n}} \\
\left(\mu \mathrm{molCO}{ }_{2} \cdot \mathrm{m}^{-2} \cdot \mathrm{s}^{-1}\right)\end{array}$ & $\begin{array}{c}g_{\mathrm{s}} \\
\left(\mathrm{molH}_{2} \mathrm{O} \cdot \mathrm{m}^{-2} \cdot \mathrm{s}^{-1}\right)\end{array}$ & $\begin{array}{c}C_{\mathrm{i}} \\
\left(\mu \mathrm{mol} \cdot \mathrm{mol}^{-1}\right)\end{array}$ & $\begin{array}{c}\text { WUE }_{\mathrm{i}} \\
\left(\mu \mathrm{molCO}{ }_{2} \cdot \mathrm{mol} \mathrm{H}_{2} \mathrm{O}^{-1}\right)\end{array}$ & $\begin{array}{c}V_{\mathrm{cmax}} \\
\left(\mu \mathrm{mol} \cdot \mathrm{m}^{-2} \cdot \mathrm{s}^{-1}\right)\end{array}$ & $\begin{array}{c}J \\
\left(\mu \mathrm{mol} \cdot \mathrm{m}^{-2} \cdot \mathrm{s}^{-1}\right)\end{array}$ & $\begin{array}{c}\Psi_{1} \\
(\mathrm{MPa})\end{array}$ \\
\hline High & $30.3 \pm 0.5$ & $1.00 \pm 0.09$ & $327 \pm 6$ & $32.8 \pm 3.4$ & $165 \pm 4$ & $177 \pm 4$ & $-1.05 \pm 0.01$ \\
\hline Low & $31.7 \pm 0.6$ & $2.80 \pm 0.09$ & $361 \pm 1$ & $11.5 \pm 0.5$ & $157 \pm 8$ & $175 \pm 4$ & $-1.00 \pm 0.02$ \\
\hline Significance & NS & $* * *$ & $* * *$ & $* * *$ & NS & NS & NS \\
\hline
\end{tabular}

Photosynthesis was measured at a PPF of $2000 \mu \mathrm{mol} \cdot \mathrm{m}^{-2} \cdot \mathrm{s}^{-1}$, an ambient $\mathrm{CO}_{2}$ concentration of $400 \mu \mathrm{mol} \cdot \mathrm{mol}^{-1}$, a leaf temperature of $28^{\circ} \mathrm{C}$, and a VPD of $0.8 \mathrm{kPa}(80 \% \mathrm{RH})$. The $P_{\mathrm{n}}$ and $g_{\mathrm{s}}$ are the same data as in Figure 1. Values are means $\pm \mathrm{SE}$ (photosynthetic properties, $\mathrm{n}=10 ; \Psi_{\mathrm{l}}, \mathrm{n}=5$ ). Significance (Student's $t$-test): NS, non-significant $(P>0.05)$; ***, $P<0.001$. 
Table 2. Stomatal and epidermal cell density, stomatal index, and stomatal length for first true leaves of Cucumis sativus acclimatized to high $(3.2 \mathrm{kPa})$ or low $(0.4 \mathrm{kPa})$ vapor-pressure-deficit $(\mathrm{VPD})$.

\begin{tabular}{|c|c|c|c|c|c|c|c|c|}
\hline \multirow{2}{*}{$\begin{array}{c}\text { Acclimatization } \\
\text { VPD }\end{array}$} & \multicolumn{2}{|c|}{$\begin{array}{l}\text { Stomatal density } \\
\left(\text { stomata } \cdot \mathrm{mm}^{-2}\right)\end{array}$} & \multicolumn{2}{|c|}{$\begin{array}{l}\text { Epidermal cell density } \\
\quad\left(\text { cells } \cdot \mathrm{mm}^{-2}\right)\end{array}$} & \multicolumn{2}{|c|}{$\begin{array}{c}\text { Stomatal index } \\
(\%)\end{array}$} & \multicolumn{2}{|c|}{$\begin{array}{l}\text { Stomatal length } \\
(\mu \mathrm{m})\end{array}$} \\
\hline & Adaxial & Abaxial & Adaxial & Abaxial & Adaxial & Abaxial & Adaxial & Abaxial \\
\hline High & $542 \pm 36$ & $820 \pm 28$ & $2548 \pm 137$ & $2381 \pm 63$ & $17.5 \pm 0.3$ & $25.6 \pm 0.4$ & $9.9 \pm 0.3$ & $9.8 \pm 0.3$ \\
\hline Low & $371 \pm 14$ & $581 \pm 17$ & $1721 \pm 355$ & $1781 \pm 27$ & $17.7 \pm 0.2$ & $24.7 \pm 0.3$ & $16.8 \pm 0.3$ & $15.4 \pm 0.2$ \\
\hline Significance & $* *$ & $* * *$ & $* *$ & $* * *$ & NS & NS & $* * *$ & $* * *$ \\
\hline
\end{tabular}

Values are means $\pm \mathrm{SE}(\mathrm{n}=5)$. Significance (Student's $t$-test): NS, non-significant $(P>0.05) ; * *, P<0.01 ; * * *, P<0.001$. The stomatal index is defined as the ratio of the number of stomata in a given area divided by the total number of stomata plus other epidermal cells in that area (Casson et al., 2009).

Acclimation VPD

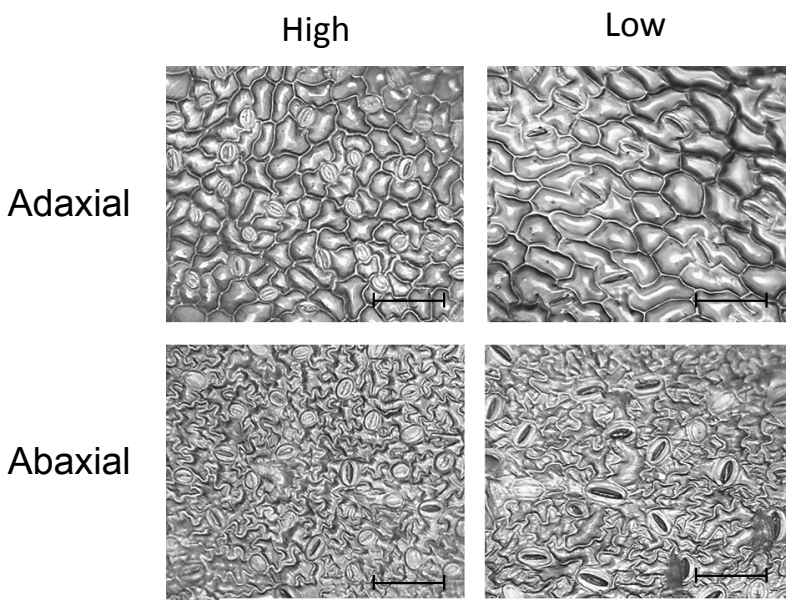

Fig. 2. Microscopic images of the adaxial and abaxial surfaces of first true leaves of Cucumis sativus acclimatized to a high $(3.2 \mathrm{kPa})$ or low $(0.4 \mathrm{kPa})$ vapor-pressure-deficit (VPD). Scale bars represent $50 \mu \mathrm{m}$. The photographs were trimmed and retouched to improve contrast from the originals.

nificantly higher for high-VPD leaves: 1.46 times the number in low-VPD leaves on the adaxial side versus 1.41 times on the abaxial side (Table 2). The epidermal cell density was also higher in the high-VPD leaves: 1.48 and 1.33 times the density on the adaxial and abaxial sides, respectively, of the low-VPD leaves (Table 2). The stomatal index did not differ significantly between the VPD treatments (Table 2). The stomatal lengths of the low-VPD leaves were significantly greater $(1.70$ and 1.57 times on the adaxial and abaxial sides, respectively) than those of the high-VPD leaves (Table 2; Fig. 2). The epidermal cells also tended to be larger in the low-VPD leaves than in the high-VPD leaves (Fig. 2).

\section{Effect of acclimatization VPD on short-term response to drought}

The $g_{\mathrm{s}}$ was greater at the start of the water-supply limitation in the low-VPD leaves (approximately 2 times that in the high-VPD leaves) (Fig. 3). $g_{\mathrm{s}}$ in both VPD leaves decreased, and then reached approximately $50 \%$ of initial levels 30 min after the treatment started.

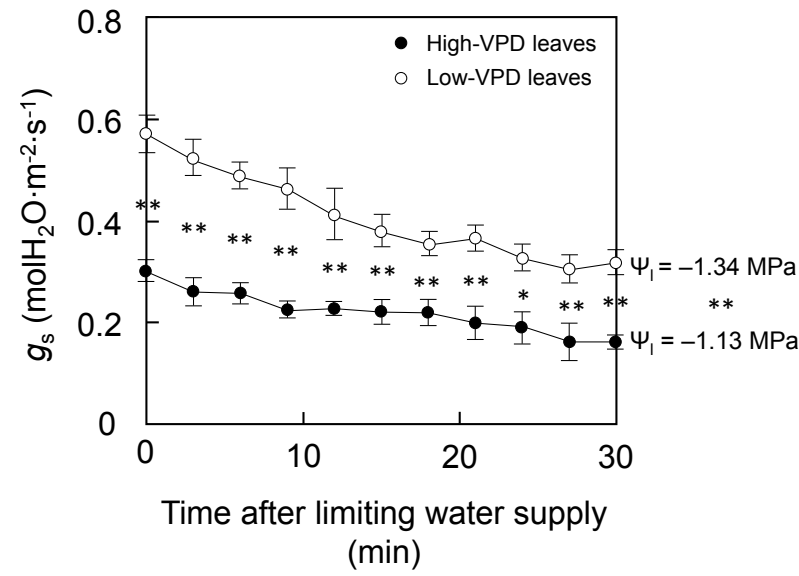

Fig. 3. Changes in stomatal conductance $\left(g_{\mathrm{s}}\right)$ of the first true leaves of Cucumis sativus that had been acclimatized to a high $(3.2 \mathrm{kPa})$ or low $(0.4 \mathrm{kPa})$ vapor-pressure-deficit (VPD), followed by water-supply limitation for up to $30 \mathrm{~min}$. Values represent the sums of adaxial and abaxial $g_{\mathrm{s}}$. Leaf water potential $\left(\Psi_{1}\right) 30$ min after limiting the water supply is shown at the right side of the graph. The water-supply limitation was conducted by exposing roots to saturated vapor conditions. The shoots of the seedlings were maintained at $28^{\circ} \mathrm{C}$ under a VPD of $1.9 \mathrm{kPa}$ (approximately $50 \% \mathrm{RH})$. Values are means $\pm \mathrm{SE}(\mathrm{n}=5)$. Significance: *, $P<0.05 ; * *, P<0.01$ (Student's $t$-test). The $g_{\text {s }}$ values cannot be directly compared with those in Table 1 because of the different measurement devices.

The values of $g_{\mathrm{s}}$ in this experiment cannot be directly compared with those in the photosynthesis measurements (Table 1) because of the different measuring devices. $g_{\mathrm{s}}$ of the high-VPD leaves was significantly lower $(\times 0.53$ at the start of the treatment; $\times 0.5130 \mathrm{~min}$ after starting the treatment) than that of the low-VPD leaves throughout the water-supply-limitation treatment (Fig. 3). $\Psi_{1}$ of the low-VPD leaves was significantly lower than that of the high-VPD leaves $30 \mathrm{~min}$ after starting the water-supply limitation (Fig. 3). As a result, wilting appeared to be more severe in the low-VPD leaves than in the high-VPD leaves (Fig. 4).

\section{Discussion}

The lack of a significant difference in the $P_{\mathrm{n}}-C_{\mathrm{i}}$ curves, $V_{\text {cmax }}$, and $J$ between the VPD treatments indicates that photosynthesis of the high-VPD leaves was 


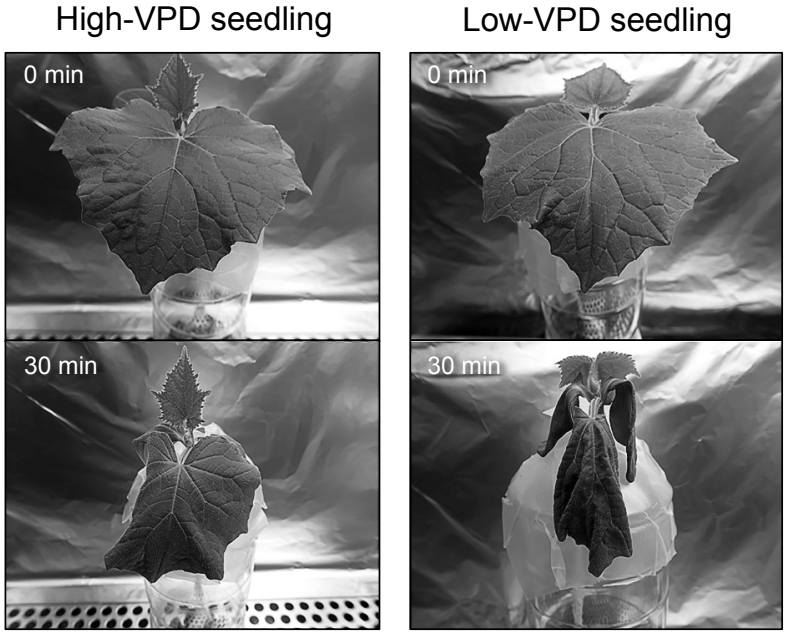

Fig. 4. Photographs of a Cucumis sativus seedling that had been acclimatized to a high $(3.2 \mathrm{kPa})$ or low $(0.4 \mathrm{kPa})$ vapor-pressuredeficit (VPD), at the start of (upper), and $30 \mathrm{~min}$ after (lower) water-supply limitation.

not limited by non-stomatal factors (i.e., carboxylation efficiency) in this experiment. This probably resulted from the fact that the high-VPD treatment did not significantly decrease $\Psi_{1}$ compared with the value in the low-VPD treatment (Table 1); decreased $\Psi_{1}$ may cause inhibition of carboxylation and thereby reduce photosynthetic efficiency (Keck and Boyer, 1974; Lawlor, 2002). This is probably because the water content of the medium was maintained at a sufficiently high level during the treatments, and the distance from the roots to the leaves was relatively short in the young plants. In addition, the high-VPD leaves had significantly reduced stomatal conductance (Table 1), which could maintain $\Psi_{1}$ at non-damaging levels by suppressing transpiration. This probably resulted from feed-forward responses of the stomata to atmospheric moisture levels: stomata decrease transpiration in response to increasing evaporative demand (Buckley, 2005; Farquhar, 1978; Grantz, 1990; Lange et al., 1971; Peak and Mott, 2011). From the $P_{\mathrm{n}}-C_{\mathrm{i}}$ curve analysis, the decrease in $C_{\mathrm{i}}$ with decreasing $g_{\mathrm{s}}$ occurred within the range in which photosynthesis is mainly limited by RuBP regeneration rather than by RuBP carboxylation; in the latter reaction, photosynthesis is strongly related to $C_{\mathrm{i}}$. Therefore, the decreased $g_{\mathrm{s}}$ in the high-VPD leaves did not significantly limit $P_{\mathrm{n}}$ via a reduction in $C_{\mathrm{i}}$ (i.e., stomatal factors) in the present study.

The leaf surface properties differed greatly between the treatments, even though the leaf areas were similar. The higher stomatal density and smaller stomatal size in the high-VPD leaves agrees with previous reports, in which stomatal density increased, but stomatal size decreased, under water stress in several species (Bosabalidis and Kofidis, 2002; Boughalleb and Hajlaoui, 2011; Hovenden et al., 2012). The higher stomatal density and smaller stomatal size influence $g_{\mathrm{s}}$ an- tagonistically and compensate for each other. Therefore, the difference in $g_{\mathrm{s}}$ between the treatments probably depends on the degree of stomatal aperture and thus represents a plastic response. This hypothesis is supported by a previous study (Shibuya et al., 2003), in which a similar VPD acclimatization was applied to the same species; in the previous study, it was found that the decreased $g_{\mathrm{s}}$ in high-VPD leaves could easily recover to the same level as that in low-VPD leaves after a 24-h low-VPD treatment following high-VPD acclimatization. The stomatal index did not differ significantly between the VPD treatments (Table 2), indicating that high VPD did not accelerate differentiation of stomata from epidermal cells. This agrees with a previous report (Hovenden et al., 2012), in which the stomatal index was not significantly affected by changes in ambient humidity. Thus, the higher stomatal density and smaller stomatal size in high-VPD leaves probably resulted from a significantly higher epidermal-cell density (Table 2), which may be caused by the limitation of epidermal-cell expansion in response to greater evaporative demand (Alves and Setter, 2004; Lecoeur et al., 1995; Tardieu et al., 2000).

The seedlings in the high-VPD treatment took 2 days longer than the low-VPD seedlings ( 10 and 8 days after seeding, respectively) to reach the same developmental stage based on the size of the first true leaves, indicating that the seedlings' growth was suppressed at high VPD. In the present study, the photosynthesis on a leafarea basis was not altered by the VPD treatments, despite the growth differences between treatments. These results sound contradictory, but probably resulted from the suppressed leaf enlargement under high-VPD conditions, which decreases photosynthesis on a whole-plant basis, thereby limiting whole-plant growth even though photosynthesis on a leaf-area basis was not suppressed. This suggests that high VPD can suppress plant growth not only through stomatal and non-stomatal photosynthetic limitation, but also through a limitation of leaf enlargement in response to greater evaporative demand; the latter is probably the main factor that contributed to growth inhibition under high VPD in the present study.

In the water-supply limitation experiment, $g_{\mathrm{s}}$ of the low-VPD leaves was greater than that of the high-VPD leaves after the start of water-supply limitation, but the low-VPD leaves showed a lower (more negative) $\Psi_{1}$ and appeared to show more severe damage (wilting) 30 min after the treatment started, indicating that the water status of the high-VPD leaves was maintained at less damaging levels by decreasing transpiration after VPD acclimatization. This result agrees with the previous reports in which high-VPD hardening reduced the transpiration of seedlings after transplantation and thereby enhanced their drought tolerance (Bañon et al., 2006; Sánchez-Blanco et al., 2004; Shibuya et al., 2003, 2006). In addition to these results, the present study demonstrated that high-VPD hardening could enhance 
the tolerance to short-term $(<30 \mathrm{~min})$ drought without stomatal or non-stomatal limitation of photosynthesis when controlling $g_{\mathrm{s}}$ effectively.

\section{Acknowledgement}

We are grateful to Dr. Ryo Matsuda (University of Tokyo) for frequent and valuable discussions.

\section{Literature Cited}

Alves, A. A. and T. L. Setter. 2004. Response of cassava leaf area expansion to water deficit: cell proliferation, cell expansion and delayed development. Ann. Bot. 94: 605-613.

Bañon, S., J. Ochoa, J. A. Franco, J. J. Alarcón and M. J. Sánchez-Blanco. 2006. Hardening of oleander seedlings by deficit irrigation and low air humidity. Environ. Exp. Bot. 56: 36-43.

Bosabalidis, A. M. and G. Kofidis. 2002. Comparative effects of drought stress on leaf anatomy of two olive cultivars. Plant Sci. 163: 375-379.

Boughalleb, F. and H. Hajlaoui. 2011. Physiological and anatomical changes induced by drought in two olive cultivars (cv Zalmati and Chemlali). Acta Physiol. Plant. 33: 53-65.

Buckley, T. N. 2005. The control of stomata by water balance. New Phytol. 168: 275-292.

Carins Murphy, M. R., G. J. Jordan and T. J. Brodribb. 2014. Acclimation to humidity modifies the link between leaf size and the density of veins and stomata. Plant Cell Environ. 37: 124-131.

Casson, S. A., K. A. Franklin, J. E. Gray, C. S. Grierson, G. C. Whitelam and A. M. Hetherington. 2009. Phytochrome B and PIF4 regulate stomatal development in response to light quantity. Curr. Biol. 19: 229-234.

Chaves, M. M., J. Osorio and J. S. Pereira. 2004. Water use efficiency and photosynthesis. p. 42-74. In: M. Bacon (ed.). Water Use Efficiency in Plant Biology. CRC Press LLC, Boca Raton.

Dai, Z., G. E. Edwards and M. S. Ku. 1992. Control of photosynthesis and stomatal conductance in Ricinus communis L. (castor bean) by leaf to air vapor pressure deficit. Plant Physiol. 99: 1426-1434.

El-Sharkawy, M. A., J. H. Cock and A. D. P. Hernandez. 1985. Stomatal response to air humidity and its relation to stomatal density in a wide range of warm climate species. Photosynth. Res. 7: 137-149.

Farquhar, G. D. 1978. Feedforward responses of stomata to humidity. Aust. J. Plant Physiol. 5: 787-800.

Flexas, J. and H. Medrano. 2002. Drought-inhibition of photosynthesis in $\mathrm{C}_{3}$ plants: stomatal and non-stomatal limitations revisited. Ann. Bot. 89: 183-189.

Grantz, D. A. 1990. Plant response to atmospheric humidity. Plant Cell Environ. 13: 667-679.

Hovenden, M. J., J. K. Vander Schoor and Y. Osanai. 2012. Rela- tive humidity has dramatic impacts on leaf morphology but little effect on stomatal index or density in Nothofagus cunninghamii (Nothofagaceae). Aust. J. Bot. 60: 700-706.

Itagaki, K., T. Shibuya, M. Tojo, R. Endo and Y. Kitaya. 2014. Atmospheric moisture influences on conidia development in Podosphaera xanthii through host-plant morphological responses. Eur. J. Plant Pathol. 138: 113-121.

Keck, R. W. and J. S. Boyer. 1974. Chloroplast response to low leaf water potentials III. Differing inhibition of electron transport and photophosphorylation. Plant Physiol. 53: 474479.

Lange, O. L., R. Lösch, E. D. Schulze and L. Kappen. 1971. Responses of stomata to changes in humidity. Planta 100: 7686.

Lawlor, D. W. 2002. Limitation to photosynthesis in waterstressed leaves: stomata vs. metabolism and the role of ATP Ann. Bot. 89: 871-885.

Lecoeur, J., J. Wery, O. Turc and F. Tardieu. 1995. Expansion of pea leaves subjected to short water deficit: cell number and cell size are sensitive to stress at different periods of leaf development. J. Exp. Bot. 46: 1093-1101.

Peak, D. and K. A. Mott. 2011. A new, vapour-phase mechanism for stomatal responses to humidity and temperature. Plant Cell Environ. 34: 162-178.

Raschke, K. and A. Resemann. 1986. The midday depression of $\mathrm{CO}_{2}$ assimilation in leaves of Arbutus unedo L.: Diurnal changes in photosynthetic capacity related to changes in temperature and humidity. Planta 168: 546-558.

Sánchez-Blanco, M. J., T. Ferrández, A. Navarro, S. Bañon and J. J. Alarcón. 2004. Effects of irrigation and air humidity preconditioning on water relations, growth and survival of Rosmarinus officinalis plants during and after transplanting. J. Plant Physiol. 161: 1133-1142.

Sharkey, T. D., C. J. Bernacchi, G. D. Farquhar and E. L. Singsaas. 2007. Fitting photosynthetic carbon dioxide response curves for C3 leaves. Plant Cell Environ. 30: 10351040.

Shibuya, T., R. Terakura, Y. Kitaya and M. Kiyota. 2006. Effects of low relative humidity and illumination on leaf water status of cucumber seedlings and growth of harvested cuttings. HortScience 41: 410-413.

Shibuya, T., R. Terakura and M. Kiyota. 2003. Effects of shortterm treatment of air humidity on growth and transpiration characteristics of cucumber seedlings, and on growth of their cuttings. Environ. Control Biol. 41: 347-352 (Japanese text with English abstract).

Tardieu, F., M. Reymond, P. Hamard, C. Granier and B. Muller. 2000. Spatial distributions of expansion rate, cell division rate and cell size in maize leaves: a synthesis of the effects of soil water status, evaporative demand and temperature. J. Exp. Bot. 51: 1505-1514.

von Caemmerer, S. and G. D. Farquhar. 1981. Some relationships between the biochemistry of photosynthesis and the gas exchange of leaves. Planta 153: 376-387. 